\title{
Modulation of Environmental Dynamics at the Active Site and Activity of an Enzyme under Nanoscopic Confinement: Subtilisin Carlsberg in Anionic AOT Reverse Micelle
}

\author{
Surajit Rakshit, Ranajay Saha, and Samir Kumar Pal* \\ Department of Chemical, Biological, and Macromolecular Sciences, S.N. Bose National Centre for Basic Sciences, Block JD, \\ Sector III, Salt Lake, Kolkata 700098, India
}

Supporting Information

\begin{abstract}
Hydration dynamics plays a crucial role in determining the structure, function, dynamics, and stability of an enzyme. These dynamics involve the trappedwater motions within small distance along with the total protein dynamics. However, the exact molecular basis for the induction of enzyme function by water dynamics is still remain unclear. Here, we have studied both enzymatic activity and environmental dynamics at the active site of an enzyme, Subtilisin Carlsberg (SC), under confined environment of the reverse micelle (RM) retaining the structural integrity of the protein. Kinetic measurements show that enzymatic activity increases with increasing the water

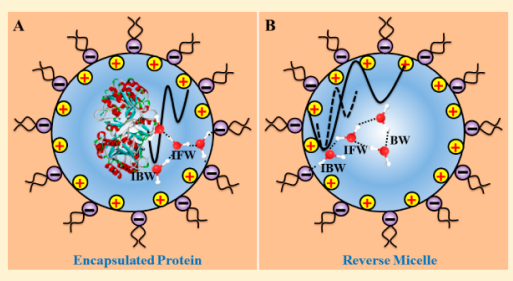
content of the RM. The picosecond-resolved fluorescence Stokes shift studies indicate faster hydration dynamics at the active site of the enzyme with increasing the water content in the RM ( $w_{0}$ values). Temperature-dependent hydration dynamics studies demonstrate the increased flexibility of the protein at higher temperature under confinement. From temperature-dependent solvation dynamics study, we have also calculated the activation energy that has to be overcome for full orientational freedom to the water molecules from bound to free-state. The results presented here establish a correlation between the enzymatic activity and dynamics of hydration of the encapsulated protein SC in cell-like confined environment within the structural integrity of the enzyme.
\end{abstract}

\section{INTRODUCTION}

The role of hydration in enzyme activity has been a longstanding unresolved problem in molecular biophysics. ${ }^{1-3}$ To understand the molecular basis of the role of water in protein function, several studies have been done to correlate a relation between enzyme activity and hydration level. Most of the studies so far aimed at elucidating the role of water in enzyme function have utilized hydrated protein powders, films, or in gas phase. ${ }^{4-7}$ For instance, Daniel et. al, examined the enzyme activity of pig liver esterage (PLE) at hydration level of $3( \pm 2)$ molecules of water per molecule of enzyme and suggested that neither hydration nor fast anharmonic dynamics (100 ps) are required for enzyme function. ${ }^{1,2,8}$ It was also concluded in the study that involvement of faster dynamics very much depends on the specific requirement of the enzyme for its function. For example, the function of light-driven proton pump protein bacteriorhodopsin exhibits a strong correlation with dynamical transition and its range from 0.1 to a few hundred picoseconds. ${ }^{9-11}$ Studies of lysozymes powders equilibrated with water in air have shown that catalysis reaction occurs at a hydration level below the monolayer water coverage $(0.2 \mathrm{~g}$ of water per gram of enzyme $) .{ }^{12}$ However, the way of importance of dynamics at the molecular level is difficult to achieve from a single experiment and is clearly missing in contemporary literature. Also, the use of enzyme powder complicates the measurement of enzyme activity, particularly at low catalytic activities. Thus, any correlation among enzyme hydration, dynamics, and activity is still not clear. A convenient way to study the water dynamics and enzyme activity is through encapsulation in reverse micelle (RM), because of the precise control of water loading properties $\left(w_{0}=[\right.$ water $] /[$ surfactant $\left.]\right)$ in the system. In earlier studies from this group, the efficacy of the $\mathrm{RM}$ environment to study protein in controlled hydration has been demonstrated. ${ }^{13,14}$ Here, we have studied both enzymatic activity and water dynamics of Subtilisin Carlsberg (SC) and have correlated the observed catalytic function with water dynamics. SC is an alkaline serine protease with a well-known three-dimensional crystal structure, ${ }^{15}$ widely used as an additive in commercial laundry products. ${ }^{16}$ The structure of the enzyme is retained in presence of wide variety of organic solvent and remains catalytically active even at low water content. ${ }^{3,7}$ Therefore, both the enzymatic activity and water dynamics of the protein can be studied over a wide range of the RM hydration. In the present work, we have measured the activity of the protein using N-CBZGly-Gly-Leu p-nitroanilide as a substrate. For solvation dynamics study, we have used 3-(dansylamino)phenylboronic acid (DB) as a solvation probe. The use of DB as a solvation probe lies in the fact that it is a potent serine protease inhibitor. ${ }^{17}$ Therefore, it is easy to monitor the change in hydration in the active site of the protein. Circular dichroism (CD) measurements have been performed to check the secondary structure of the encapsulated protein with different degrees of hydration. From the detailed analysis of the temperature dependent solvation dynamics, we have calculated

Received: June 21, 2013

Revised: August 23, 2013

Published: September 4, 2013 
activation energy barrier $\left(E_{\text {act }}\right)$ between free and bound type of water present in the solvation shell of the protein and the strength of the hydrogen bonds.

\section{MATERIALS AND METHODS}

Chemicals. Lyophilized SC powder was purchased from Sigma. N-CBZ-Gly-Gly-Leu p-nitroanilide (CBZ-GGL-pNA) (Sigma), 3-(dansylamino)phenylboronic acid (DB) (Sigma), iso-octane (Spectrochem), sodium bis(2-ethylhexyl) sulfosuccinate, (AOT) (Fluka), disodium hydrogen phosphate dihydrate (Sigma), and sodium dihydrogen phosphate dihydrate (Sigma) were used as received.

Experimental and Analytical Procedures. Protein solutions were prepared in $20 \mathrm{mM}$ phosphate buffer solution at $\mathrm{pH} 7.0$ using double distilled water. Concentration of SC in aqueous solution was determined using the extinction coefficient value of $\varepsilon=23.46 \mathrm{mM}^{-1} \mathrm{~cm}^{-1}$ at $278 \mathrm{~nm}$. Protein in $\mathrm{RM}$ was prepared as follows: first, AOT solutions were prepared by dissolving solid AOT in iso-octane. The final AOT concentration was made $100 \mathrm{mM}$. The requisite amount of aqueous protein solution was then added to the $100 \mathrm{mM}$ AOT solution to make desired $w_{0}$ values with gentle shaking for several minutes. The binding of $\mathrm{DB}$ to $\mathrm{SC}$ was achieved by adding $\mathrm{DB}$ to the protein solution with overnight incubation at $4{ }^{\circ} \mathrm{C}$ with constant stirring. The enzyme concentration is maintained higher than that of the probe DB in order to avoid free DB in solution.

Enzymatic activity of SC has been determined by using the kinetic mode of the UV spectrophotometer using the substrate CBZ-GGL-pNA. The extinction coefficient used for determining the concentration of CBZ-GGL-pNA in buffer $(\mathrm{pH}=7.0)$ is $14 \mathrm{mM}^{-1} \mathrm{~cm}^{-1}$ (at $315 \mathrm{~nm}$ ). ${ }^{18}$ For the kinetics experiment, the concentration of SC was maintained at $1 \mu \mathrm{M}$, whereas that of the substrate was maintained at $850 \mu \mathrm{M}$. The rate of formation of product was monitored by observing the change in the absorbance at $410 \mathrm{~nm}$ of the product with time. The extinction coefficients of the products formed is $8.8 \mathrm{mM}^{-1} \mathrm{~cm}^{-1}$ (at $410 \mathrm{~nm}$ ).

Dynamic light scattering (DLS) measurements were done with a Nano $S$ Malvern instrument employing a $4 \mathrm{~mW} \mathrm{He}-\mathrm{Ne}$ laser $(\lambda=632.8 \mathrm{~nm})$ equipped with a thermostatted sample chamber. All the scattered photons are collected at $173^{\circ}$ scattering angle. The scattering intensity data are processed using the instrumental software to obtain the hydrodynamic diameter $\left(d_{\mathrm{H}}\right)$ and the size distribution of the scatterer in each sample. The instrument measures the time-dependent fluctuation in the intensity of light scattered from the scatter in solution at a fixed scattering angle. $d_{\mathrm{H}}$ of the scatter is estimated from the intensity autocorrelation function of the time-dependent fluctuation in intensity. $d_{\mathrm{H}}$ is defined as

$$
d_{\mathrm{H}}=\frac{k_{\mathrm{b}} T}{3 \pi \eta D}
$$

where $k_{\mathrm{b}}$ is the Boltzmann constant, $\eta$ is the viscosity, and $D$ is the translational diffusion coefficient. In a typical size distribution graph from the DLS measurement, the $X$-axis shows a distribution of size changes in nanometers, while the $Y$-axis shows the relative intensity of the scattered light.

Steady-state absorption and emission were measured with Shimadzu Model UV-2450 spectrophotometer and Horiba Jobin Yvon Fluorolog 3 fluorimeter respectively. The circular dichroism measurements were performed on a Jasco 810 spectropolarimeter with protein concentration of $0.28 \mathrm{mg} \mathrm{mL}^{-1}$ using a cell of $0.1 \mathrm{~cm}$ path length. The secondary structure content of the protein after and before encapsulation in the RM was estimated by using the CDNN software program ${ }^{19}$ and K2D analysis. ${ }^{20}$ Thermal unfolding of the encapsulated protein was monitored by recording far-UV CD at $222 \mathrm{~nm}$ as a function of temperature. The temperature was raised from 20 to $70{ }^{\circ} \mathrm{C}$ in $2{ }^{\circ} \mathrm{C}$ steps with 2 min equilibration time at each temperature.

All the fluorescence transients were recorded using picosecondresolved time correlated single photon counting (TCSPC) technique at $54.7^{\circ}$ (magic angle) with respect to polarization axis of the excitation beam. The TCSPC setup was from Edinburgh instruments, U.K. (excitation wavelength $375 \mathrm{~nm}$, 80 ps instrument response function (IRF)) and fitted using FAST software provided by Edinburgh Instruments. The details of time-resolved measurements could be found elsewhere. ${ }^{21-23}$ The time-dependent fluorescence Stokes shifts, as estimated from time-resolved emission spectroscopy (TRES), were used to construct the normalized spectral shift correlation function or the solvent correlation function, $C(t)$, defined as

$$
C(t)=\frac{\nu(t)-\nu(\infty)}{\nu(0)-\nu(\infty)}
$$

where $\nu(0), \nu(\mathrm{t})$, and $\nu(\infty)$ are the emission maxima $\left(\right.$ in $\left.\mathrm{cm}^{-1}\right)$ at time zero, $t$, and infinity, respectively. The $\nu(\infty)$ values had been taken to be the emission frequency beyond which an insignificant or no spectral shift was observed. The $C(t)$ function represents the temporal response of the solvent relaxation process, as occurs around the probe following its photoexcitation and the associated change in the dipole moment. For temporal fluorescence anisotropy measurements, emission polarization was adjusted to be parallel or perpendicular to that of the excitation and anisotropy is defined as

$$
r(t)=\frac{\left[I_{\|}(t)-I_{\perp}(t)\right]}{\left[I_{\|}(t)+2 I_{\perp}(t)\right]}
$$

\section{RESULTS AND DISCUSSIONS}

$\mathrm{RM}$ is a tiny aqueous droplet, surrounded and stabilized by a monolayer of surfactant molecules, and dispersed in a water immiscible organic solvent. Addition of proteins in the RM causes encapsulation of the protein inside the aqueous core of the RM. ${ }^{13}$ Figure 1 shows DLS spectra of the RM with different degrees of hydration in the presence and absence of the protein, SC. Similar peak position of spectra confirms the complete encapsulation of protein inside the RM core. However, hydrogen bonding properties of interfacial water is found to be distinct from bulk water. Therefore, it is expected that the confined water molecules of the RM will affect the conformational properties of the encapsulated protein as well. To quantitatively compare our results with the expectation, we have monitored the conformational change of the protein using far-UV CD spectra. A comparison of the $\mathrm{CD}$ structure of free and encapsulated protein is shown in Figure 2a. A change in CD structure of the encapsulated protein is observed relative to the free protein in buffer. Appearance of two minima at 208 and $222 \mathrm{~nm}$ is indicative of the helical content of the protein. Thus the protein undergoes a significant increase in $\alpha$-helicity when introduced into AOT RM compared to that in aqueous buffer solution. Analysis of the spectra by CDNN/ $\mathrm{K} 2 \mathrm{D}$ analysis indeed reveals that $\alpha$-helix content of SC increases after encapsulation in AOT RM (Tables 1 and 2). As shown in Table 1 , the content of $\alpha$-helix, $\beta$-sheet, $\beta$-turn, and random coil structure of SC in aqueous buffer are 33.6, 17.5, 17.3, and $31.6 \%$ respectively, which are in excellent agreement with that 


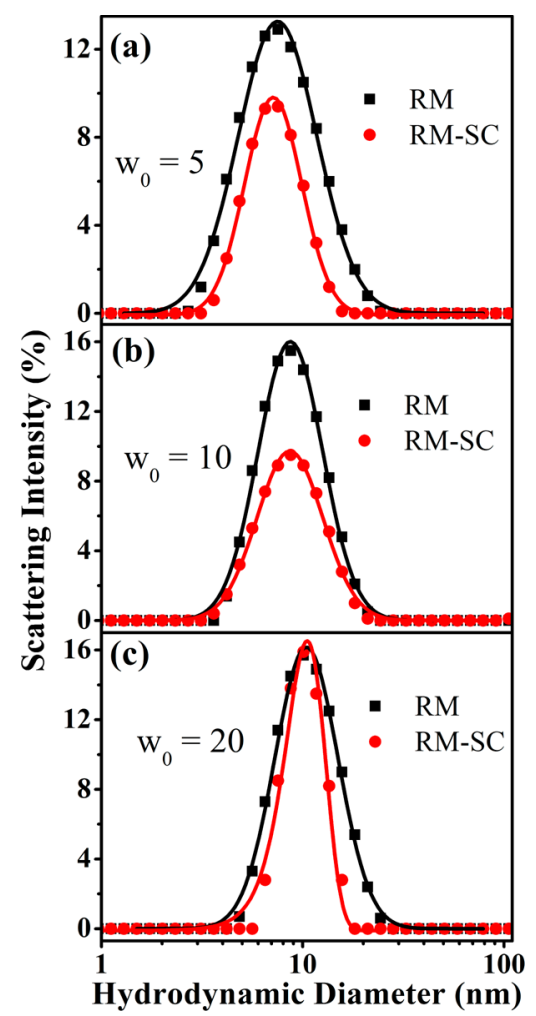

Figure 1. $(a-c)$ Dynamics light scattering spectra of reverse micelle in presence and absence of the enzyme, Subtilisin Carlsberg. The solid lines are guide to the eye.
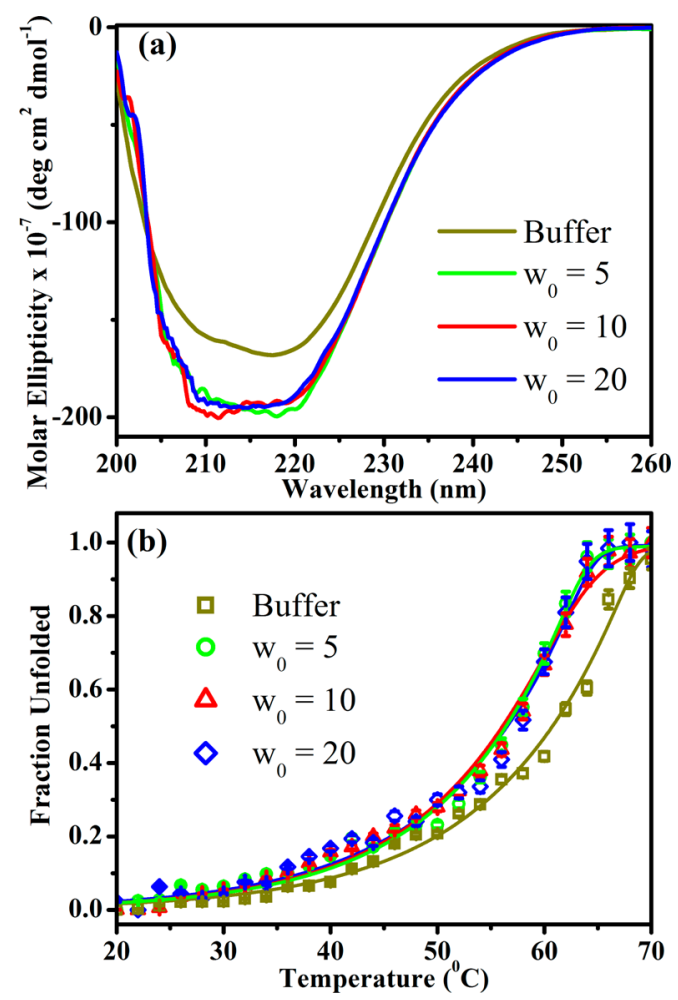

Figure 2. (a) Far-UV CD spectra of Subtilisin Carlsberg at various $w_{0}$ values. (b) Fraction of unfolded protein in buffer and encapsulated in reverse micelle of various $w_{0}$ values, as a function of temperature. The estimated error in measurement is about $2 \%$.
Table 1. Percentages of $\alpha$-Helix, $\beta$-Structure, $\beta$-Turn, and Random Coil of SC in Buffer and in RM of Different Degrees of Hydration, Calculated from CDNN Analysis with Standard Error of $\sim 2 \%$

\begin{tabular}{lccccc} 
system & $\begin{array}{c}\alpha \text {-helix } \\
(\%)\end{array}$ & $\begin{array}{c}\text { antiparallel } \\
(\%)\end{array}$ & $\begin{array}{c}\text { parallel } \\
(\%)\end{array}$ & $\begin{array}{c}\beta \text {-turn } \\
(\%)\end{array}$ & $\begin{array}{c}\text { random coil } \\
(\%)\end{array}$ \\
buffer & 33.60 & 8.85 & 8.65 & 17.30 & 31.60 \\
$w_{0}=5$ & 41.14 & 7.25 & 7.25 & 16.48 & 27.88 \\
$w_{0}=10$ & 41.74 & 7.17 & 7.17 & 16.40 & 27.52 \\
$w_{0}=20$ & 40.00 & 7.40 & 7.40 & 16.50 & 28.70 \\
\hline
\end{tabular}

Table 2. Percentages of $\boldsymbol{\alpha}$-helix and $\boldsymbol{\beta}$-sheet (parallel and antiparallel) of SC in buffer and in RM of different degrees of hydration, calculated from K2D analysis with standard error of $\sim 2 \%$

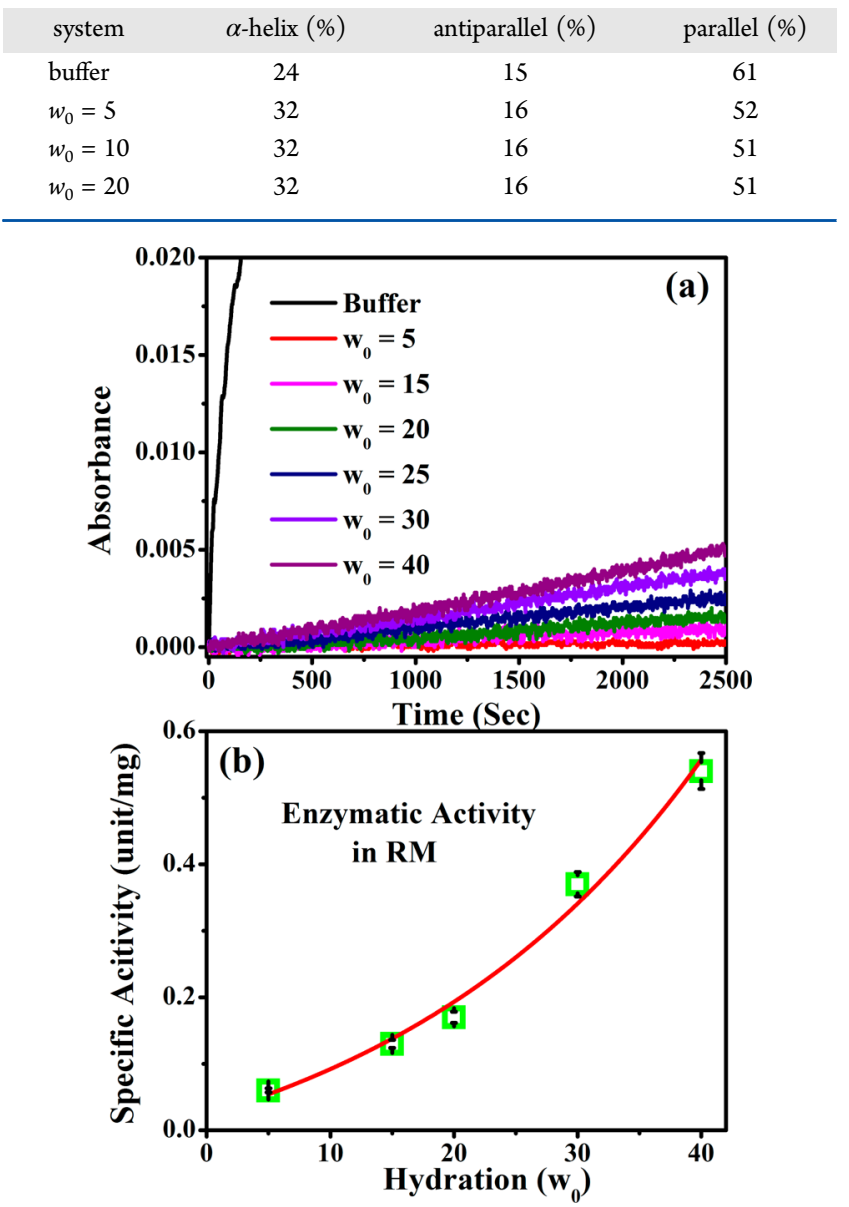

Figure 3. (a) Enzymatic activity of SC in buffer and in RM with different $w_{0}$ values. (b) Change in specific activity of SC with changing $w_{0}$ values of the AOT RM. Solid line is guide to eye. The estimated error in measurement is about $3 \%$.

calculated from the X-ray structure ${ }^{24}$ and the report of Griebenow using Fourier transform infrared (FTIR) spectroscopy. ${ }^{25}$ However, after encapsulation of protein in RM the $\alpha$-helix content increases from $33.6 \%$ in aqueous solution to $41.1 \%$ in the AOT RM. We have noted that the estimation of $\alpha$-helix content depends on the analysis software used (Tables 1 and 2). The increased helical content of the protein $\mathrm{SC}$ in $\mathrm{RM}$ is not surprising given the fact that in the RM confinement, most of the water molecules are hydrogen bonded to the negatively charged sulfosuccinate head groups of the AOT 
Table 3. Comparison of Specific Activity in units/mg of SC in Buffer and in RM with Different $w_{0}$ Values with Standard Error of $\sim 5 \%$ a

$\begin{array}{lc}\text { system } & \text { specific activity (units/mg) } \\ \text { buffer } & 14.87 \\ w_{0}=5 & 0.06 \\ w_{0}=15 & 0.12 \\ w_{0}=20 & 0.17 \\ w_{0}=30 & 0.39 \\ w_{0}=40 & 0.54\end{array}$

${ }^{a}$ According to vendor (Sigma-Aldrich) one unit of SC will hydrolyze casein to produce color equivalent to $1.0 \mu$ mole $(181 \mu \mathrm{g})$ of tyrosine per min at $\mathrm{pH} 7.5$ at $37^{\circ} \mathrm{C}$ (color by Folin-Ciocalteu reagent). The specific activity of the native SC is $7-15$ units $/ \mathrm{mg}$.

molecules leaving very few water molecules to interact with the protein SC. Therefore, the extent of hydrogen bonding between the amide group of the protein and water molecules decreases, consequently interhelical hydrogen bonds in such an environment are strengthened. Similar results are also observed for other proteins in surfactant solutions. ${ }^{26-30}$ However, the molar ellipticity remains unaltered with increasing the $w_{0}$ values indicating the positioning of SC near the surface of the RM. In order to obtain more insight on the stability of the protein due to confinement effect, the thermal unfolding transition experiments are carried out. As shown in Figure $2 b$, the thermal unfolding curves obtained by recording $\mathrm{CD}$ signal of the encapsulated protein at $222 \mathrm{~nm}$ exhibit different thermal melting behaviors $\left(\sim 58^{\circ} \mathrm{C}\right)$ than that of the free protein $\left(64{ }^{\circ} \mathrm{C}\right)$ in aqueous solution. This destabilization may arise due to the geometrical confinement effect of the RM, as RM is reported to have two opposing effects on helical structure: stabilization due to backbone dehydration and destabilization due to geometrical confinement, ${ }^{30}$ where the latter appears to be dominating in our experiment. However, as shown in Figure 2 and Tables 1 and 2, after encapsulation there is no such change either in $\alpha$-helix content or in thermal stability of the protein with increasing degrees of hydration.

Figure 3a shows enzymatic activity of the protein SC in the AOT RM with various degrees of hydration $\left(w_{0}\right)$ within the structural integrity of the protein in the nanoenvironments. The estimated specific activity (Figure $3 b$; Table 3 ) is found to be increased with increasing degree of hydration. Scheme 1 shows the mechanistic pathways for the hydrolysis of the substrate CBZ-GGL-pNA by SC. Briefly, in the first step the nucleophile (Ser-221) attacks the substrate to form an acyl-enzyme intermediate followed by deacylation in the second step. In the final step, water act as a nucleophile, which hydrolyzes the ester bond between the substrate and Ser-221 of the enzyme to form the final hydrolysis products. The distinct difference in enzymatic activity of the protein even at higher $w_{0}$ values compared to bulk buffer again suggests the positioning of the enzyme near the surface of the RM. In order to correlate the change of enzymatic activity of the protein with water dynamics at the active site, we have used time-dependent fluorescence stokes shift (TDFSS) method using the fluorescence behavior of the enzyme inhibitor, $\mathrm{DB}$, attached to the active site of the enzyme. Figure $4 \mathrm{~b}$ shows the fluorescence decay transients of SC-DB adduct in the RM of $w_{0}=$ 5 at three selected wavelengths at room temperature. The decay transient at the blue end $(430 \mathrm{~nm})$ can be fitted triexponentially with the time components of 180 ps (47\%), 1.03 ns (44\%), and $4.10 \mathrm{~ns}(9 \%)$, whereas at the extreme red wavelength $(590 \mathrm{~nm})$ the transient shows rise components of $480 \mathrm{ps}$ and $1.95 \mathrm{~ns}$ along with a decay component of $10 \mathrm{~ns}$. The presence of faster decay components at the blue end and rise component at the red wavelength in contrast to the protein in aqueous solution is

Scheme 1. Schematic Representation of the Mechanistic Pathway for Substrate Hydrolysis by the Enzyme SC ${ }^{a}$
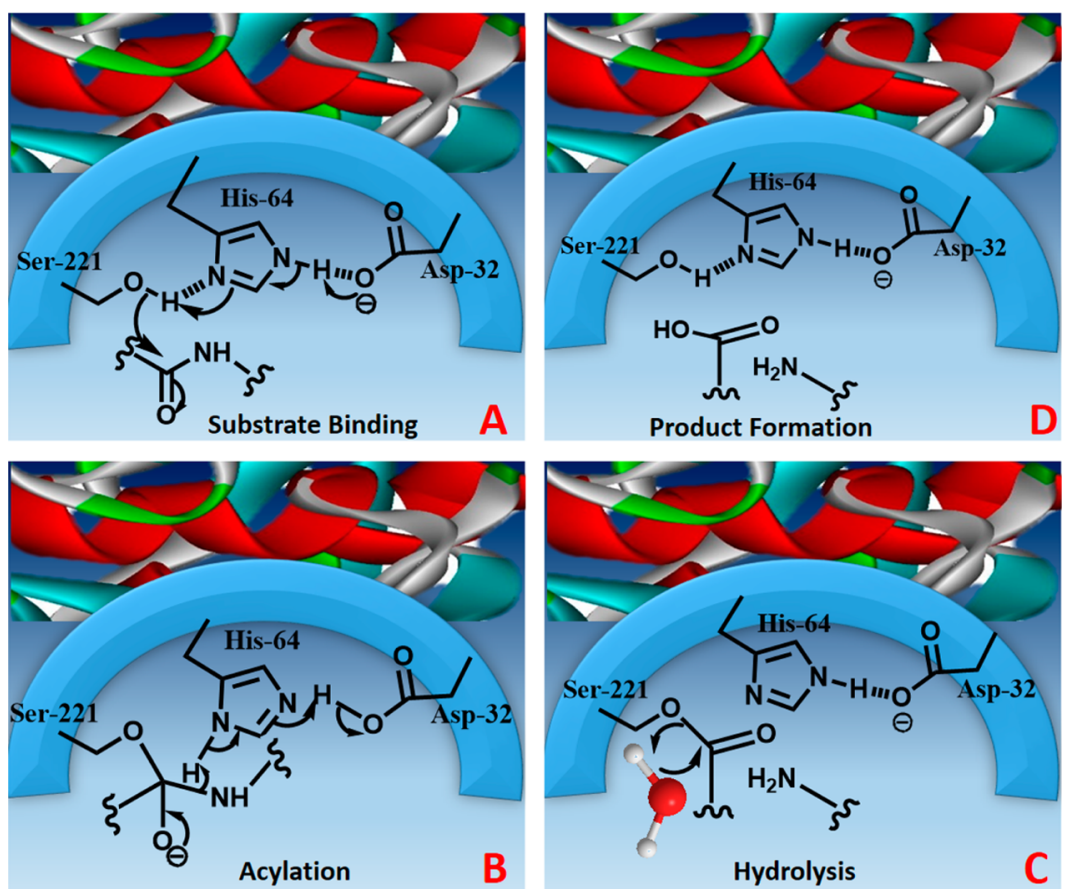

${ }^{a}$ In the first step, the nucleophile (Ser-221) attacks the substrate (CBZ-GGL-pNA) to form an acyl-enzyme intermediate followed by deacylation in the second step. In the final step, water acts as nucleophile that hydrolyzes the ester bond between the substrate and Ser-221 of the enzyme to form the final hydrolysis products. 

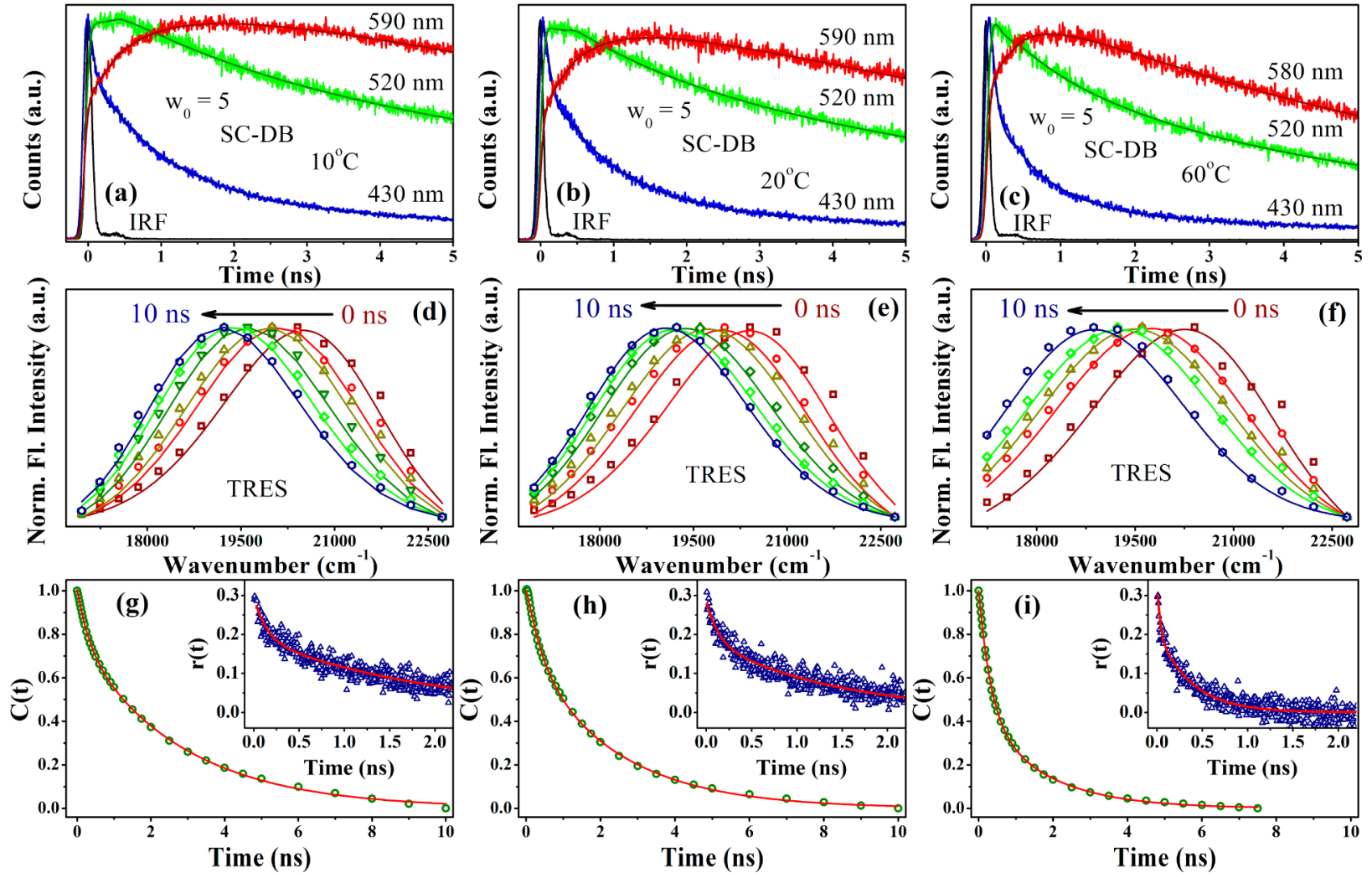

Figure 4. $(a-c)$ Fluorescence decay transients of 3-(dansylamino)phenylboronic acid bound to Subtilisin Carlsberg, encapsulated within AOT reverse micelle of $w_{0}=5$ at different temperatures. $(\mathrm{d}-\mathrm{f}, \mathrm{g}-\mathrm{i})$ Corresponding TRES and $C(t)$, respectively. The corresponding anisotropy decay profiles, $r(t)$, are shown in the inset of panels $\mathrm{g}-\mathrm{i}$. The estimated error in measurement is about $2 \%$.

Table 4. Time Constants for $C(t)$ and $r(t)$ of SC in RM Using DB As Fluorescent Probe at Various Temperatures with Standard Error of $\sim 5 \%^{a}$

\begin{tabular}{|c|c|c|c|c|c|c|c|c|c|c|c|c|}
\hline \multirow[b]{2}{*}{$w_{0}$} & \multirow[b]{2}{*}{ temperature $\left({ }^{\circ} \mathrm{C}\right)$} & \multirow[b]{2}{*}{ emission peak (nm) } & \multicolumn{5}{|c|}{ solvation time constants } & \multirow[b]{2}{*}{$E_{\text {act }}\left(\mathrm{kcal} \mathrm{mol}^{-1}\right)$} & \multicolumn{4}{|c|}{ rotational time constants } \\
\hline & & & $a_{1}$ & $\tau_{1}(\mathrm{~ns})$ & $a_{2}$ & $\tau_{2}(\mathrm{~ns})$ & $\left\langle\tau_{\mathrm{av}}\right\rangle(\mathrm{ns})$ & & $a_{1}$ & $\tau_{1}$ (ns) & $a_{2}$ & $\overline{\tau_{2}(\mathrm{~ns})}$ \\
\hline \multirow[t]{6}{*}{5} & 10 & 508 & 0.23 & 0.32 & 0.77 & 2.78 & 2.23 & $3.3 \pm 0.02$ & 0.35 & 0.13 & 0.65 & 1.95 \\
\hline & 20 & 512 & 0.30 & 0.41 & 0.70 & 2.35 & 1.77 & & 0.34 & 0.12 & 0.66 & 1.39 \\
\hline & 30 & 515 & 0.23 & 0.25 & 0.77 & 1.33 & 1.08 & & 0.23 & 0.11 & 0.77 & 0.75 \\
\hline & 40 & 517 & 0.52 & 0.42 & 0.48 & 2.10 & 1.23 & & 0.29 & 0.06 & 0.71 & 0.59 \\
\hline & 50 & 518 & 0.54 & 0.37 & 0.46 & 1.75 & 1.00 & & 0.32 & 0.05 & 0.68 & 0.48 \\
\hline & 60 & 519 & 0.56 & 0.32 & 0.44 & 1.69 & 0.92 & & 0.36 & 0.02 & 0.64 & 0.38 \\
\hline \multirow[t]{6}{*}{10} & 10 & 518 & 0.51 & 0.63 & 0.49 & 2.90 & 1.75 & $3.4 \pm 0.02$ & 0.07 & 0.29 & 0.16 & 1.82 \\
\hline & 20 & 520 & 0.70 & 0.58 & 0.30 & 3.19 & 1.37 & & 0.07 & 0.12 & 0.18 & 0.94 \\
\hline & 30 & 523 & 0.71 & 0.45 & 0.29 & 2.20 & 0.96 & & 0.08 & 0.16 & 0.14 & 0.10 \\
\hline & 40 & 525 & 0.70 & 0.38 & 0.30 & 2.10 & 0.89 & & 0.07 & 0.16 & 0.14 & 0.91 \\
\hline & 50 & 526 & 0.74 & 0.30 & 0.26 & 2.30 & 0.82 & & 0.10 & 0.15 & 0.13 & 0.64 \\
\hline & 60 & 526 & 0.69 & 0.26 & 0.31 & 1.80 & 0.74 & & 0.11 & 0.24 & 0.09 & 0.67 \\
\hline \multirow[t]{6}{*}{20} & 10 & 524 & 0.49 & 0.37 & 0.51 & 1.65 & 1.02 & $3.5 \pm 0.02$ & 0.09 & 0.22 & 0.17 & 1.42 \\
\hline & 20 & 527 & 0.58 & 0.29 & 0.42 & 1.37 & 0.74 & & 0.10 & 0.21 & 0.15 & 1.23 \\
\hline & 30 & 528 & 0.61 & 0.24 & 0.39 & 1.19 & 0.60 & & 0.12 & 0.18 & 0.13 & 1.06 \\
\hline & 40 & 529 & 0.69 & 0.22 & 0.31 & 1.12 & 0.50 & & 0.10 & 0.11 & 0.14 & 0.66 \\
\hline & 50 & 529 & 0.74 & 0.20 & 0.26 & 1.02 & 0.42 & & 0.12 & 0.10 & 0.13 & 0.53 \\
\hline & 60 & 529 & 0.73 & 0.20 & 0.26 & 1.00 & 0.41 & & 0.15 & 0.12 & 0.09 & 0.61 \\
\hline
\end{tabular}

${ }^{a} \tau_{i}$ represents the time constants, $a_{i}$ represents its relative contribution, and $\left\langle\tau_{s}\right\rangle\left(=\Sigma a_{i} \tau_{i}\right)$ is the average solvation time constant.

indicative of slower solvation of the probe in the encapsulated protein. From these decay transients, we construct the timeresolved emission spectra (TRES) as shown in Figure 4e, which is associated with a significant dynamical Stokes shift of $1350 \mathrm{~cm}^{-1}$ in $10 \mathrm{~ns}$. Following TRES, we have constructed the solvent correlation function, $C(t)$ using eq 2 . The temporal decay of the $C(t)$ shows biexponential decay with time constants of $410 \mathrm{ps}$ and $2.35 \mathrm{~ns}$ (Figure $4 \mathrm{~h}$ and Table 4 ). Previous theoretical ${ }^{31}$ and experimental ${ }^{18,32-34}$ studies on hydration at biointerfaces have revealed that the interfacial waters are hydrogen bonded to the biomolecular interface and show slower dynamics than that of bulk water. The slow components in solvation dynamics may 

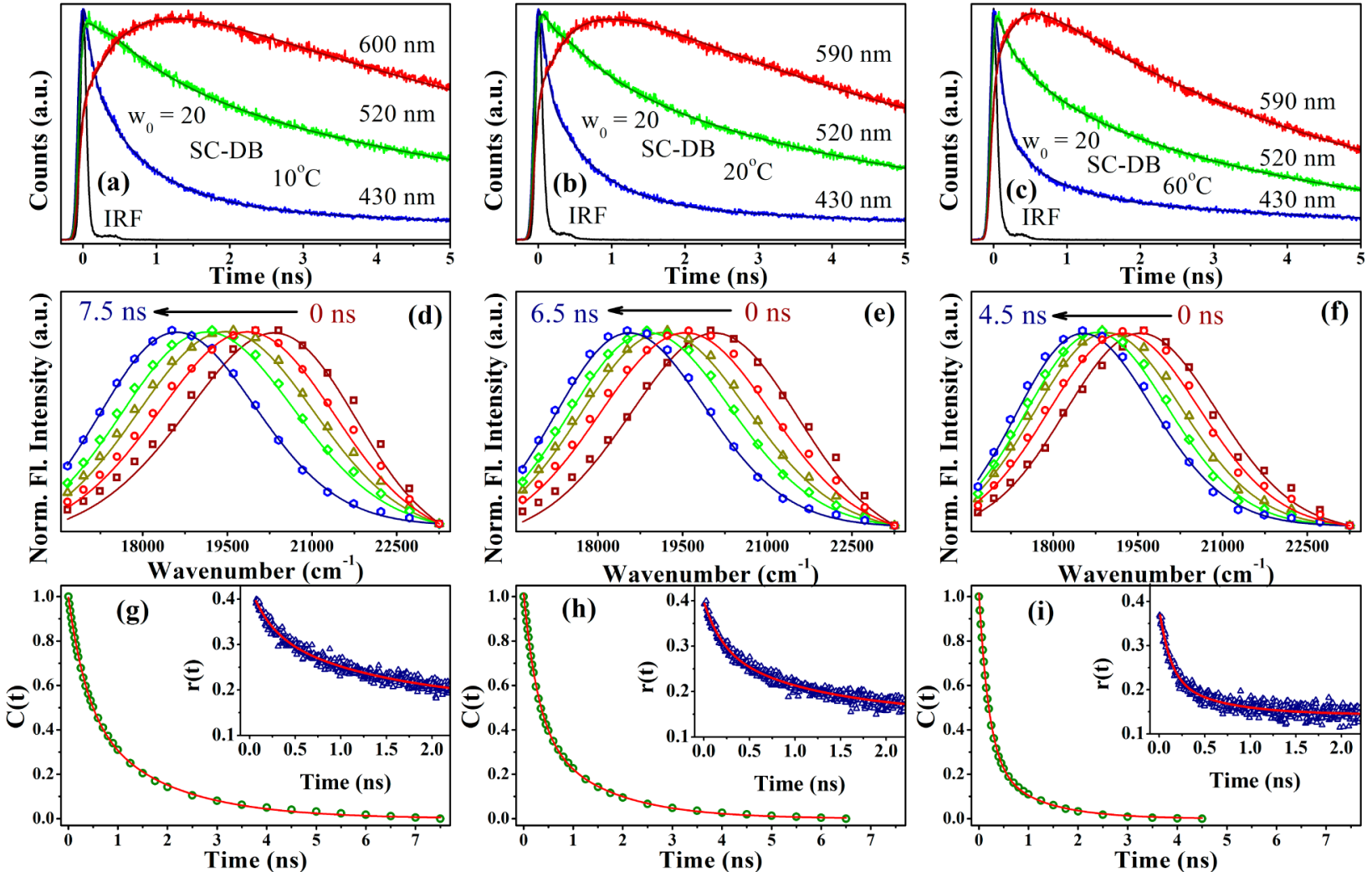

Figure 5. $(\mathrm{a}-\mathrm{c})$ Fluorescence decay transients of 3-(dansylamino)phenylboronic acid bound to Subtilisin Carlsberg, encapsulated within AOT reverse micelle of $w_{0}=20$ in different temperatures. $(\mathrm{d}-\mathrm{f}, \mathrm{g}-\mathrm{i})$ Corresponding TRES and $C(t)$, respectively. The corresponding anisotropy decay profiles, $r(t)$ are shown in the inset of panels $\mathrm{g}-\mathrm{i}$. The estimated error in measurement is about $2 \%$.
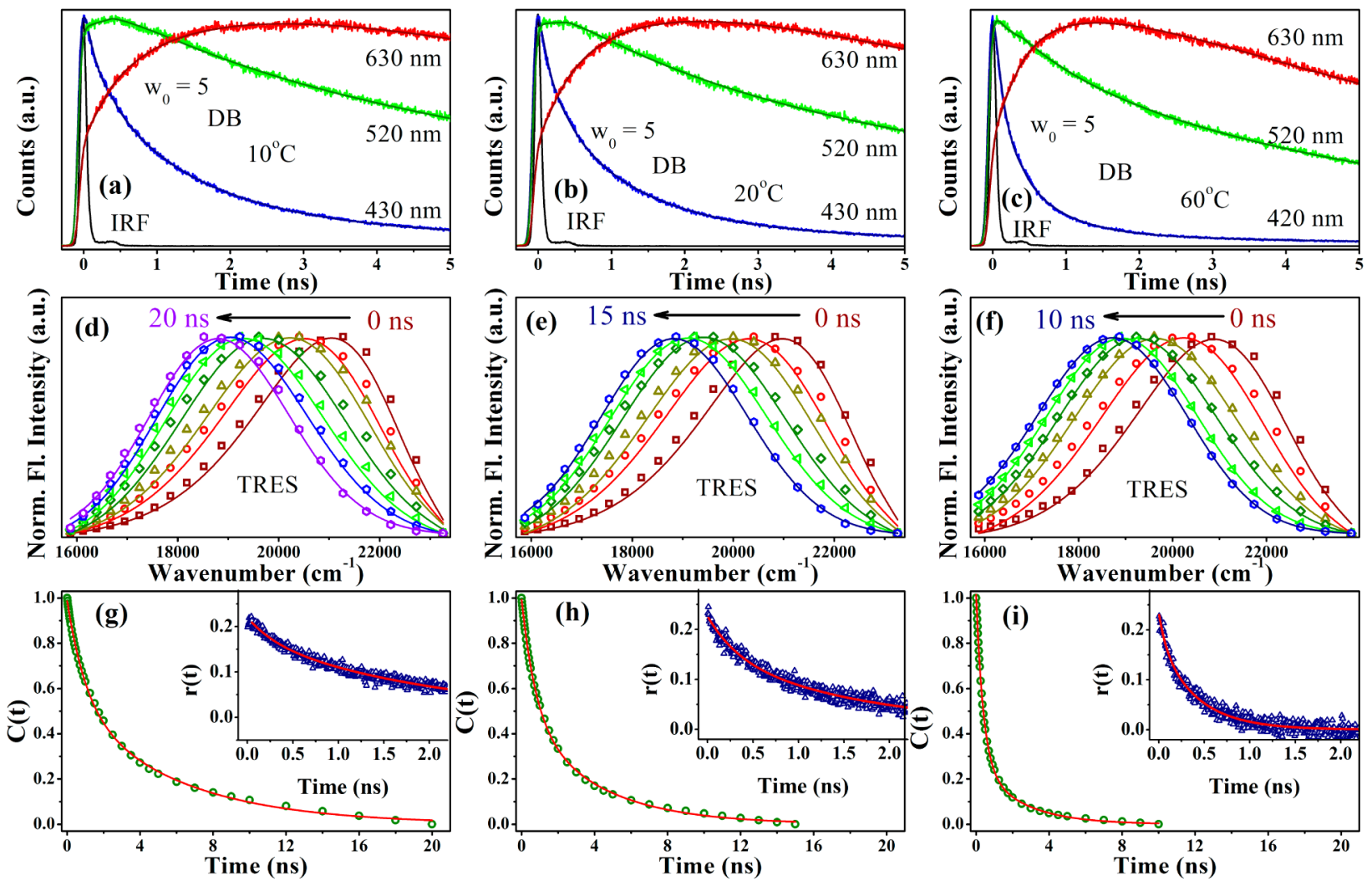

Figure 6. $(\mathrm{a}-\mathrm{c})$ Fluorescence decay transients of 3-(dansylamino)phenylboronic acid in AOT reverse micelle of $w_{0}=5$ in different temperatures as a control study. $(\mathrm{d}-\mathrm{f}, \mathrm{g}-\mathrm{i})$ Corresponding TRES and $C(t)$, respectively. The corresponding anisotropy decay profiles, $r(t)$ are shown in the inset of panels $\mathrm{g}-\mathrm{i}$. The estimated error in measurement is about $2 \%$. 

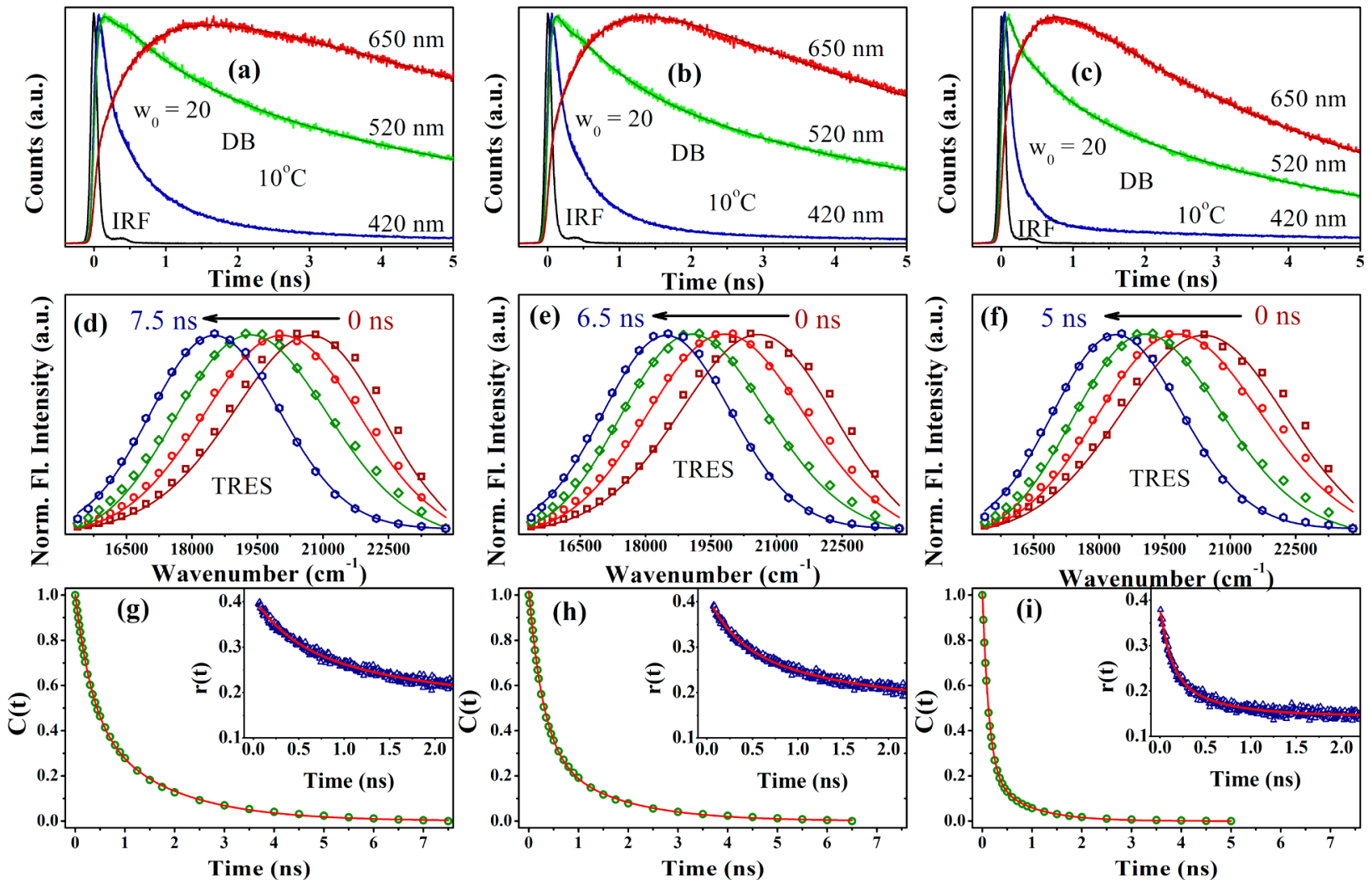

Figure 7. (a-c) Fluorescence decay transients of 3-(dansylamino)phenylboronic acid in AOT reverse micelle of $w_{0}=20$ in different temperatures as a control study. $(\mathrm{d}-\mathrm{f}, \mathrm{g}-\mathrm{i})$ Corresponding TRES and $C(t)$, respectively. The corresponding anisotropy decay profiles, $r(t)$ are shown in the inset of panels $\mathrm{g}-\mathrm{i}$. The estimated error in measurement is about $2 \%$.

Table 5. Time Constants for $C(t)$ and $r(t)$ of DB in RM at Various Temperatures with Standard Error of $\sim 5 \%{ }^{a}$

\begin{tabular}{|c|c|c|c|c|c|c|c|c|c|c|c|c|}
\hline \multirow[b]{2}{*}{$w_{0}$} & \multirow[b]{2}{*}{ temperature $\left({ }^{\circ} \mathrm{C}\right)$} & \multirow[b]{2}{*}{ emission peak (nm) } & \multicolumn{5}{|c|}{ solvation time constants } & \multirow[b]{2}{*}{$E_{\text {act }}\left(\mathrm{kcal} \mathrm{mol}^{-1}\right)$} & \multicolumn{4}{|c|}{ rotational time constants } \\
\hline & & & $a_{1}$ & $\tau_{1}(\mathrm{~ns})$ & $a_{2}$ & $\tau_{2}(\mathrm{~ns})$ & $\left\langle\tau_{\mathrm{av}}\right\rangle(\mathrm{ns})$ & & $a_{1}$ & $\tau_{1}(\mathrm{~ns})$ & $a_{2}$ & $\tau_{2}(\mathrm{~ns})$ \\
\hline \multirow[t]{6}{*}{5} & 10 & 508 & 0.45 & 1.03 & 0.55 & 5.83 & 3.66 & $3.5 \pm 0.02$ & 0.22 & 0.30 & 0.78 & 2.16 \\
\hline & 20 & 512 & 0.52 & 0.78 & 0.48 & 3.97 & 2.33 & & 0.36 & 0.36 & 0.64 & 1.82 \\
\hline & 30 & 516 & 0.66 & 0.72 & 0.34 & 4.09 & 1.87 & & 0.47 & 0.34 & 0.53 & 1.58 \\
\hline & 40 & 518 & 0.65 & 0.52 & 0.35 & 2.39 & 1.18 & & 0.25 & 0.15 & 0.75 & 0.71 \\
\hline & 50 & 519 & 0.71 & 0.44 & 0.29 & 2.49 & 1.03 & & 0.24 & 0.06 & 0.76 & 0.47 \\
\hline & 60 & 520 & 0.73 & 0.39 & 0.27 & 2.36 & 0.92 & & 0.25 & 0.08 & 0.75 & 0.41 \\
\hline \multirow[t]{5}{*}{10} & 10 & 520 & 0.49 & 0.56 & 0.51 & 2.32 & 1.46 & $4.3 \pm 0.04$ & 0.07 & 0.29 & 0.16 & 1.84 \\
\hline & 20 & 523 & 0.61 & 0.45 & 0.39 & 2.20 & 1.13 & & 0.09 & 0.08 & 0.19 & 0.94 \\
\hline & 30 & 526 & 0.74 & 0.40 & 0.26 & 2.05 & 0.83 & & 0.11 & 0.11 & 0.14 & 1.04 \\
\hline & 40 & 527 & 0.74 & 0.31 & 0.26 & 1.68 & 0.66 & & 0.07 & 0.17 & 0.13 & 0.94 \\
\hline & 50 & 528 & 0.74 & 0.30 & 0.26 & 1.75 & 0.67 & & 0.11 & 0.11 & 0.14 & 0.60 \\
\hline \multirow[t]{6}{*}{20} & 10 & 526 & 0.52 & 0.33 & 0.48 & 1.54 & 0.91 & $5.0 \pm 0.08$ & 0.11 & 0.44 & 0.14 & 2.21 \\
\hline & 20 & 529 & 0.67 & 0.29 & 0.33 & 1.42 & 0.66 & & 0.10 & 0.32 & 0.14 & 1.50 \\
\hline & 30 & 531 & 0.72 & 0.22 & 0.28 & 1.27 & 0.51 & & 0.12 & 0.23 & 0.13 & 1.17 \\
\hline & 40 & 532 & 0.75 & 0.17 & 0.25 & 1.08 & 0.40 & & 0.14 & 0.16 & 0.12 & 0.87 \\
\hline & 50 & 533 & 0.79 & 0.16 & 0.21 & 0.96 & 0.33 & & 0.13 & 0.14 & 0.11 & 0.64 \\
\hline & 60 & 533 & 0.79 & 0.13 & 0.21 & 0.78 & 0.27 & & 0.14 & 0.12 & 0.09 & 0.53 \\
\hline
\end{tabular}

${ }^{a} \tau_{i}$ represents the time constants, $a_{i}$ represents its relative contribution, and $\left\langle\tau_{\mathrm{s}}\right\rangle\left(=\Sigma a_{i} \tau_{i}\right)$ is the average solvation time constant.

be due to several reasons, for example, self-diffusion of probe (DB), tumbling of the protein, local relaxation of the protein matrix, and dynamic exchange between bound and free water. The minimal change in time-dependent full width half-maxima in TRES (Figures 4 and 5) suggests the insignificant contribution from self-diffusion of the probe in the solvation response. ${ }^{35}$ Tumbling motion or reorientation of the entire protein molecule causes time scale of around 10-100 ns, which is markedly higher than time components realized for DB in SC (Table 4). ${ }^{35}$ Therefore, in the present study, the origin of the slow component might be due to the collective contribution from both the boundtype water as well as from the segmental motion of the protein residues. As the probe $\mathrm{DB}$ resides into the enzyme pocket of the protein, hence there should be a contribution from the protein residue. Similar result is also reported earlier by Sahu et. $\mathrm{al}^{36}$ where they showed slow solvation time component (4.5 ns) for 
ANS bound to BSA. We have also studied the solvation dynamics of the encapsulated protein at different temperatures. Figure 4 shows the temperature-dependent solvation dynamics study at three representative temperatures $\left(10,20\right.$, and $\left.60{ }^{\circ} \mathrm{C}\right)$ of the protein in the AOT RM at $w_{0}=5$. With an increase in temperature, the average solvation time constant, $\left\langle\tau_{s}\right\rangle\left(=\sum a_{i} \tau_{i}\right)$, becomes faster (Table 4) revealing increased flexibility of the protein with associated interfacial water at higher temperature. The increased flexibility of the protein at higher temperature is also reflected from the faster rotational anisotropy data of the probe at higher temperature (inset, Figure $4 g-i$ ). Supporting Information Figure S1 and Figure 5 shows the dynamics at the active site of the protein in the AOT RM in higher degree of hydration $\left(w_{0}=10\right.$ and 20$)$ at different temperatures. It is clear from the studies that with increase in $w_{0}$, the solvation dynamics at a particular temperature becomes faster attributing less confinement effect with increasing $w_{0}$. $^{37,38}$

In order to study the role of the protein in the slower dynamics of solvation at the active site, in a series of control experiments we have investigated the solvation dynamics of the RM without protein, using the probe DB (Figures 6 and 7 and Supporting Information Figure S2; Table 5). The observed solvation time constants are quite similar to the previous studies in AOT RM systems and are attributed to the interfacial bound-type and freetype water molecules, respectively. ${ }^{39}$ The dependency of average solvation time constant in different degrees of hydration and in different temperatures is found to be similar to those at the active site of the protein in the AOT RM, however, in a different way as shown in Figure 8. From the temperature-induced acceleration of solvation dynamics of water in encapsulated protein and free RM, we have calculated the free energy of activation from bound to

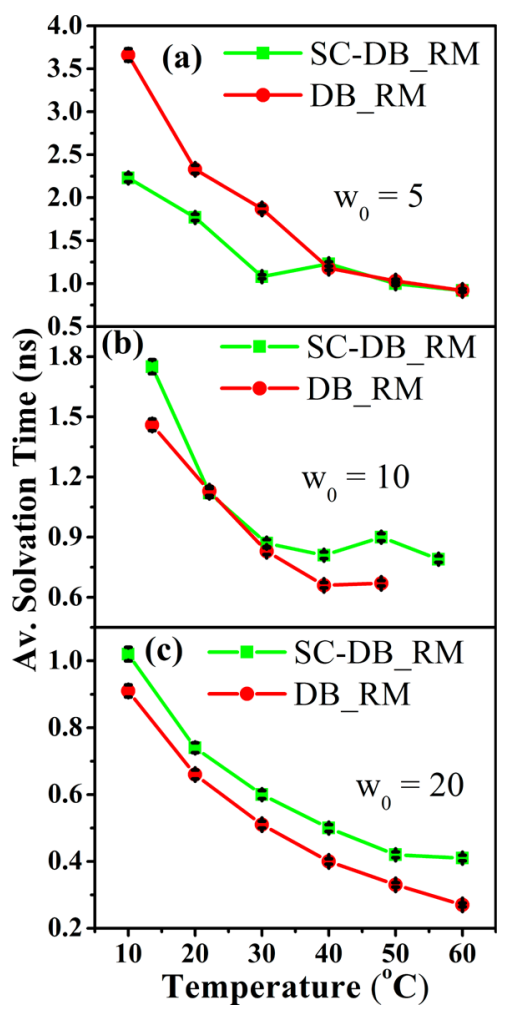

Figure 8. Comparison of the average solvation time constant of free 3-(dansylamino)phenylboronic acid and bound to Subtilisin Carlsberg encapsulated within reverse micelle of different $w_{0}$ values. The estimated error in measurement is about $2 \%$. free water molecules using multishell continuum model proposed by Bagchi et al. ${ }^{31}$ Briefly, the water molecules at the interface comprise two components: one is "free water" and the other is attached to the biomolecule by a strong hydrogen bond and rotates only in a coupled fashion with the slowly rotating biomolecule. The latter species is termed "bound water" and there is always a dynamic exchange between the free and bound water. The energetic of this bound-to-free-type transition of water molecules with temperature is assumed to be governed by an Arrhenius type of activation energy barrier crossing model $^{22,23,31}$ as follows

$$
k_{\mathrm{bf}} \approx \frac{1}{\left\langle\tau_{\mathrm{s}}\right\rangle}=A \exp \left(\frac{-E_{\mathrm{act}}}{R T}\right)
$$

where $\left\langle\tau_{\mathrm{s}}\right\rangle$ represents the average solvation time constant, $k_{\mathrm{bf}}$ is the rate constant for bound-to-free water conversion, $A$ is the pre-exponential factor, and $E_{\text {act }}$ is the corresponding activation energy for the transition process. Plot of $\ln \left(1 /\left\langle\tau_{s}\right\rangle\right)$ versus $1 / T$ produces good linear fits (Figure 9) with corresponding

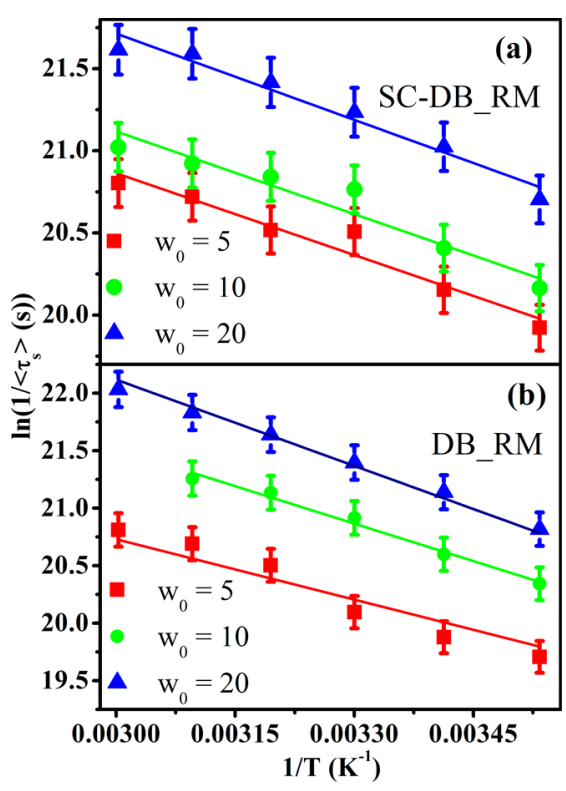

Figure 9. Plot of $\ln \left(1 / \tau_{\mathrm{s}}\right)$ against $1 / T$ for for $\mathrm{AOT} / \mathrm{i}$-Oc RM with $w_{0}=5$, 10 , and 20 in presence (a) and absence (b) of the enzyme, SC. Straight lines are fitting of the experimental data using eq 4 (see text). The estimated error is about $1 \%$.

activation energy values of $3.3,3.4$, and $3.5 \mathrm{kcal} \mathrm{mol}^{-1}$ for protein encapsulated in $w_{0}=5,10$, and $20 \mathrm{RMs}$, respectively, whereas activation energy values for free $\mathrm{RM}$ are 4.0, 4.3, and $5.0 \mathrm{kcal} \mathrm{mol}^{-1}$ respectively. The observed $E_{\text {act }}$ values for protein free $\mathrm{RM}$ are in good agreement with our previous result using C500 as solvation probe. ${ }^{40}$ It has to be noted that energy barrier calculated for $w_{0}=5$ is relatively lower and this could be because at $w_{0}=5$, RM has only two types of water molecules, namely interfacial bound water (IBW, water molecules hydrogen bonded to protein surface or AOT head groups) and interfacial free water (IFW, water molecules hydrogen bonded to IBW) (Scheme 2A, B) and this type of conversion is associated with an energy barrier of 2.4-4 $\mathrm{kcal} \mathrm{mol}^{-1} .{ }^{41}$ However, for the higher $w_{0}$ values $(\geq 10)$, the $\mathrm{RM}$ water pool is formed and the probe senses a transition from IBW to bulk-type (BW) water molecules (Scheme 2B) that is associated with a higher energy barrier of $7-8 \mathrm{kcal} \mathrm{mol}^{-1}$. ${ }^{42}$ However, in the encapsulated protein there is only two types of 
Scheme 2. Schematic Representation of the Different Types of Water Molecules IBW, IFW, and BW ${ }^{a}$
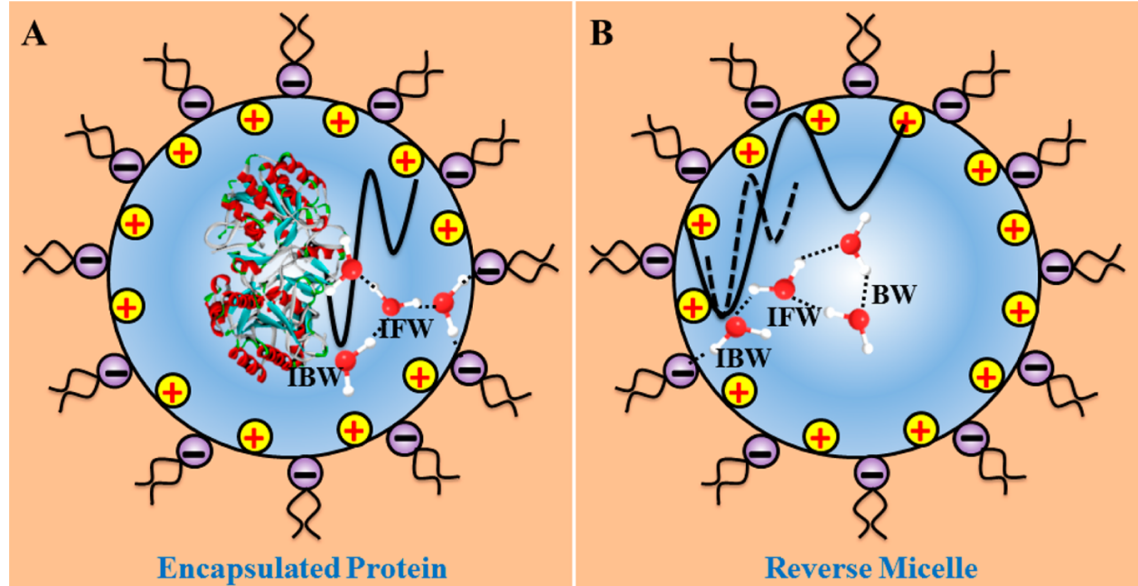

${ }^{a}$ For encapsulated protein there are mainly two types of water molecules irrespective of the hydration number due to hydration sharing by both protein and surfactant head group. Thus, the $E_{\text {act }}$ is almost same. However for RM, with increasing hydration number ( $\left.\geq 10\right)$ bulk type (BW) of water molecules generates. Therefore, the $E_{\text {act }}$ increases (see text).

water molecules (IBW and IFW) as shown in Scheme 2A, and bulk-type water is not formed even at higher $w_{0}$ values due to the competitive sharing of hydration water between the protein and surfactant molecules. This makes the $E_{\text {act }}$ value to be remain same at all the $w_{0}$ values of the encapsulated protein, although $\left\langle\tau_{s}\right\rangle$ changes due to the increased fraction of interracially free water (IFW) at higher $w_{0}$ values. Thus the dynamics and energetics of water molecules at the active site of the enzyme is correlated with the degree of hydration and differentiated from the free reverse micelle.

\section{CONCLUSION}

In conclusions, the study presented here investigates the structure, function and dynamics of SC in AOT RM. The solvation dynamics at the active site of the enzyme becomes faster with increasing $w_{0}$ values of the AOT RM. The observed acceleration of faster dynamics is due to increased content of interfacial free type (IFW) of water molecules at higher $w_{0}$ values. $\mathrm{CD}$ result suggests the helical content of the protein to be increased in AOT RM compared to free aqueous buffer, which remains unaltered by changing $w_{0}$ values. However, the enzymatic activity is found to be increased with increasing water content in the RM. The genesis of the observation appears to stem from the hydrolysis characteristics of the reaction between CBZ-GGLpNA and SC, where water act as nucleophile (Scheme 1). Faster hydration dynamics at the active site of the enzyme with increasing water content causes an increase in local polarity around the active site due to the hydration of polar and charged groups. The increase in polarity increases the active site flexibility, which in turn facilitates the hydrolysis reaction. The increased activity of the enzyme at higher hydration also supports the fact that global structural intactness is not an accurate indication of the active site flexibility. The temperature-dependent hydration dynamics supports the general view that the mobility of the water molecules in protein surface or RM increases with temperature due to the transition of surface bound water to free water at elevated temperature, which is also revealed by the Arrhenius type of energy barrier crossing model. The result presented here establish the fact that hydration dynamics has an important role on the functionality of an enzyme.

\section{ASSOCIATED CONTENT}

\section{Supporting Information}

Fluorescence decay transients; time-resolved emission spectra (TRES); solvent correlation function, $C(t)$; anisotropy decay profiles, $r(t)$ of DB bound to SC, encapsulated in AOT RM and free $\mathrm{DB}$ in AOT RM of $w_{0}=10$ in different temperatures. This material is available free of charge via the Internet at http://pubs.acs.org.

\section{AUTHOR INFORMATION}

\section{Corresponding Author}

*E-mail: skpal@bose.res.in. Telephone: +91-33-2335 5705/6/7/8. Fax: +91-33-2335-3477.

\section{Notes}

The authors declare no competing financial interest.

\section{ACKNOWLEDGMENTS}

S.R. thanks CSIR for fellowship. We thank DST for the financial support (No. DST/TM/SERI/2k11/103 and No. SB/S1/PC011/2013).

\section{REFERENCES}

(1) Daniel, R. M.; Dunn, R. V.; Finney, J. L.; Smith, J. C. The Role of Dynamics in Enzyme Activity. Annu. Rev. Biophys. Biomol. Struct. 2003, 32, 69-92.

(2) Lopez, M.; Kurkal-Siebert, V.; Dunn, R. V.; Tehei, M.; Finney, J. L.; Smith, J. C.; Daniel, R. M. Activity and Dynamics of an Enzyme, Pig Liver Esterase, in Near-Anhydrous Conditions. Biophys. J. 2010, 99, L62-L64.

(3) Affleck, R.; Xu, Z. F.; Suzawa, V.; Focht, K.; Clark, D. S.; Dordick, J. S. Enzymatic Catalysis and Dynamics in Low-Water Environments. Proc. Natl. Acad. Sci. U.S.A. 1992, 89, 1100-1104.

(4) Létisse, F.; Lamare, S.; Legoy, M.-D.; Graber, M. Solid/Gas Biocatalysis: An Appropriate Tool to Study the Influence of Organic Components on Kinetics of Lipase-Catalyzed Alcoholysis. Biochim. Biophys. Acta 2003, 1652, 27-34.

(5) Lind, P. A.; Daniel, R. M.; Monk, C.; Dunn, R. V. Esterase Catalysis of Substrate Vapour: Enzyme Activity Occurs at Very Low Hydration. Biochim. Biophys. Acta 2004, 1702, 103-110.

(6) Graber, M.; Bousquet-Dubouch, M.-P.; Sousa, N.; Lamare, S.; Legoy, M.-D. Water Plays a Different Role on Activation Thermodynamic Parameters of Alcoholysis Reaction Catalyzed by Lipase in Gaseous and Organic Media. Biochim. Biophys. Acta 2003, 1645, 56-62. 
(7) Zaks, A.; Klibanov, A. M. Enzymatic Catalysis in Nonaqueous Solvents. J. Biol. Chem. 1988, 263, 3194-3201.

(8) Daniel, R. M.; Smith, J. C.; Ferrand, M.; Héry, S.; Dunn, R.; Finney, J. L. Enzyme Activity below the Dynamical Transition at $220 \mathrm{~K}$. Biophys. J. 1998, 75, 2504-2507.

(9) Fitter, J.; Lechner, R. E.; Dencher, N. A. Picosecond Molecular Motions in Bacteriorhodopsin from Neutron Scattering. Biophys. J. 1997, 73, 2126-2137.

(10) Lehnert, U.; Réat, V.; Weik, M.; Zaccaï, G.; Pfister, C. Thermal Motions in Bacteriorhodopsin at Different Hydration Levels Studied by Neutron Scattering: Correlation with Kinetics and Light-Induced Conformational Changes. Biophys. J. 1998, 75, 1945-1952.

(11) Ferrand, M.; Dianoux, A. J.; Petry, W.; Zaccaï, G. Thermal Motions and Function of Bacteriorhodopsin in Purple Membranes: Effects of Temperature and Hydration Studied by Neutron Scattering. Proc. Natl. Acad. Sci. U.S.A. 1993, 90, 9668-9672.

(12) Rupley John, A.; Yang, P. H.; Tollin, G. Thermodynamic and Related Studies of Water Interacting with Proteins. ACS. Symp. Ser. 1980, 127, 111-132.

(13) Biswas, R.; Pal, S. K. Caging Enzyme Function: $\alpha$-Chymotrypsin in Reverse Micelle. Chem. Phys. Lett. 2004, 387, 221-226.

(14) Saha, R.; Rakshit, S.; Verma, P. K.; Mitra, R. K.; Pal, S. K. ProteinCofactor Binding and Ultrafast Electron Transfer in Riboflavin Binding Protein under the Spatial Confinement of Nanoscopic Reverse Micelles. J. Mol. Recognit. 2013, 26, 59-66.

(15) Bott, R.; Ultsch, M.; Kossiakoff, A.; Graycar, T.; Katz, B.; Power, S. The Three-Dimensional Structure of Bacillus Amyloliquefaciens Subtilisin at 1.8 A and an Analysis of the Structural Consequences of Peroxide Inactivation. J. Biol. Chem. 1988, 263, 7895-7906.

(16) Durham, D. R. Utility of Subtilisin GX as a Detergent Additive. J. Appl. Microbiol. 1987, 63, 381-386.

(17) Smoum, R.; Rubinstein, A.; Dembitsky, V. M.; Srebnik, M. Boron Containing Compounds as Protease Inhibitors. Chem. Rev. 2012, 112, $4156-4220$.

(18) Kamal, J. K. A.; Xia, T.; Pal, S. K.; Zhao, L.; Zewail, A. H. Enzyme Functionality and Solvation of Subtilisin Carlsberg: From Hours to Femtoseconds. Chem. Phys. Lett. 2004, 387, 209-215.

(19) Böhm, G.; M. R.; Jaenicke, R. Quantitative Analysis of Protein Far UV Circular Dichroism Spectra by Neural Networks. Protein Eng. 1992, $5,191-5$.

(20) Andrade, M. A.; Chacón, P.; Merelo, J. J.; Morán, F. Evaluation of Secondary Structure of Proteins from UV Circular Dichroism Spectra Using an Unsupervised Learning Neural Network. Protein Eng. 1993, 6, 383-390.

(21) Rakshit, S.; Goswami, N.; Pal, S. K. Slow Solvent Relaxation Dynamics of Nanometer Sized Reverse Micellar Systems Through Tryptophan Metabolite, Kynurenine. Photochem. Photobiol. 2012, 88, $38-45$.

(22) Rakshit, S.; Saha, R.; Chakraborty, A.; Pal, S. K. Effect of Hydrophobic Interaction on Structure, Dynamics, and Reactivity of Water. Langmuir 2013, 29, 1808-1817.

(23) Rakshit, S.; Saha, R.; Verma, P. K.; Pal, S. K. Role of Solvation Dynamics in Excited State Proton Transfer of 1-Naphthol in Nanoscopic Water Clusters Formed in a Hydrophobic Solvent. Photochem. Photobiol. 2012, 88, 851-859.

(24) Neidhart, D. J.; Petsko, G. A. The Refined Crystal Structure of Subtilisin Carlsberg at 2.5 Å Resolution. Protein Eng. 1988, 2, 271-276.

(25) Griebenow, K.; Klibanov, A. M. Can Conformational Changes be Responsible for Solvent and Excipient Effects on the Catalytic Behavior of Subtilisin Carlsberg in Organic Solvents? Biotechnol. Bioeng. 1997, 53, $351-362$.

(26) Celej, M. S.; D’Andrea, M. G.; Campana, P. T.; Fidelio, G. D.; Bianconi, M. L. Superactivity and Conformational Changes on AlphaChymotrypsin upon Interfacial Binding to Cationic Micelles. Biochem. J. 2004, 378, 1059-1066.

(27) Viseu, M. I.; Carvalho, T. I.; Costa, S. M. B. Conformational Transitions in $\beta$-Lactoglobulin Induced by Cationic Amphiphiles: Equilibrium Studies. Biophys. J. 2004, 86, 2392-2402.
(28) Andrade, S. M.; Carvalho, T. I.; Viseu, M. I.; Costa, S. M. B. Conformational Changes of $\beta$-Lactoglobulin in Sodium bis(2-ethylhexyl) Sulfosuccinate Reverse Micelles. Eur. J. Biochem. 2004, 271, 734744.

(29) Rakshit, S.; Saha, R.; Verma, P. K.; Mitra, R. K.; Pal, S. K. Ultrafast electron transfer in riboflavin binding protein in macromolecular crowding of nano-sized micelle. Biochimie 2012, 94, 2673-2680.

(30) Mukherjee, S.; Chowdhury, P.; Gai, F. Tuning the Cooperativity of the Helix-Coil Transition by Aqueous Reverse Micelles. J. Phys. Chem. B 2006, 110, 11615-11619.

(31) Nandi, N.; Bagchi, B. Dielectric Relaxation of Biological Water. J. Phys. Chem. B 1997, 101, 10954-10961.

(32) Pal, S. K.; Peon, J.; Zewail, A. H. Biological Water at the Protein Surface: Dynamical Solvation Probed Directly with Femtosecond Resolution. Proc. Natl. Acad. Sci. U.S.A. 2002, 99, 1763-1768.

(33) Pal, S. K.; Zewail, A. H. Dynamics of Water in Biological Recognition. Chem. Rev. 2004, 104, 2099-2123.

(34) Verma, P. K.; Rakshit, S.; Mitra, R. K.; Pal, S. K. Role of Hydration on the Functionality of a Proteolytic Enzyme $\alpha$-Chymotrypsin under Crowded Environment. Biochimie 2011, 93, 1424-1433.

(35) Bhattacharyya, K.; Bagchi, B. On the Origin of the Anomalous Ultraslow Solvation Dynamics in Heterogeneous Environments. J. Chem. Sci. 2007, 119, 113-121.

(36) Sahu, K.; Mondal, S. K.; Ghosh, S.; Roy, D.; Sen, P.; Bhattacharya, K. Temperature Dependence of Solvation Dynamics and Anisotropy Decay in a Protein. ANS in Bovine Serum Albumin. J. Chem. Phys. 2006, 124, 124909-124909-7.

(37) Amararene, A.; Gindre, M.; Le Huerou, J. Y.; Nicot, C.; Urbach, W.; Waks, M. Water Confined in Reverse Micelles: Acoustic and Densimetric Studies. J. Phys. Chem. B 1997, 101, 10751-10756.

(38) Carlstroem, G.; Halle, B. Water Dynamics in Microemulsion Droplets. A Nuclear Spin Relaxation Study. Langmuir 1988, 4, 13461352.

(39) Verma, P. K.; Makhal, A.; Mitra, R. K.; Pal, S. K. Role of Solvation Dynamics in the Kinetics of Solvolysis Reactions in Microreactors. Phys. Chem. Chem. Phys. 2009, 11, 8467-8476.

(40) Mitra, R. K.; Sinha, S. S.; Pal, S. K. Temperature-Dependent Solvation Dynamics of Water in Sodium Bis(2-ethylhexyl)sulfosuccinate/Isooctane Reverse Micelles. Langmuir 2008, 24, 49-56.

(41) Pal, S.; Balasubramaian, S.; Bagchi, B. Temperature Dependence of Water Dynamics at an Aqueous Micellar Surface: Atomistic Molecular Dynamics Simulation Studies of a Complex System. J. Chem. Phys. 2002, 117, 2852-2859.

(42) Sen, S.; Mukherjee, S.; Halder, A.; Bhattacharyya, K. Temperature Dependence of Solvation Dynamics in a Micelle. 4-Aminophthalimide in Triton X-100. Chem. Phys. Lett. 2004, 385, 357-361. 